\title{
Pea-Fusarium solani Interactions Contributions of a System Toward Understanding Disease Resistance
}

\author{
Lee A. Hadwiger
}

Department of Plant Pathology, Washington State University, Pullman 99164.

Accepted for publication 18 December 2007.

\begin{abstract}
Hadwiger, L. A. 2008. Pea-Fusarium solani interactions contributions of a system toward understanding disease resistance. Phytopathology 98:372-379.

This mini-review points to the usefulness of the pea-Fusarium solani interaction in researching the biochemical and molecular aspects of the nonhost resistance components of peas. This interaction has been researched to evaluate the resistance roles of the phytoalexin, pisatin, the

cuticle barrier, and the activation of the nonhost resistance response. Concurrently, evaluations of associated signaling processes and the tools possessed by the pathogen to contend with host obstacles were included. The properties of some pathogenesis-related genes of pea and their regulation and contribution to resistance are discussed. A proposed action of two biotic elicitors on both chromatin conformation and the architectural transcription factor, $\mathrm{HMG} \mathrm{A}$, is presented and includes time lines of events within the host immune response.
\end{abstract}

There are various model systems of host-parasite interactions that have contributed to our knowledge of signaling. This minireview will focus on disease resistance features, present and generated in the interactions between pea and Fusarium solani. Initially, both pea seedling and pea endocarp tissue systems were developed for studying the induction of the antifungal phytoalexin pisatin (17). Pisatin production is dependent on a series of secondary enzymes; some such as phenylalanine ammonia-lyase (PAL) and chalcone synthase (CHS) are also regarded as pathogenesis-related (PR) proteins (67). Some enzymes in the pisatin pathway are yet to be characterized and this work is in progress by DiCenzo and VanEtten (24). Other PR proteins have the potential to be directly antifungal, such as the defensins. The seedling (15) and pod endocarp (18) tissues of the pea system each have some important uses for evaluating genetical, biochemical, and developmental changes. The seedling tissue is useful in following the gradual natural infection process in the region of stem proximal to the seed both in excised stem sections and in infections under natural conditions of the field or greenhouse. The endocarp tissue of the greenhouse-grown pod is useful in assessing a rapid defense response of its epidermal cells that (28) clearly distinguishes susceptibility to the pea pathogen from resistance to nonpathogens.

The communication between pathogen and the endocarp layer of immature pea pods ( 1 to $2 \mathrm{~cm}$ ) is rapid because it is not obstructed by a well-developed cuticle layer $(32,33)$. The endocarp epidermal cells are exposed by gently separating the two freshly harvested pod halves with a smooth spatula. The observation of cell viability in a UV microscope following treatment with fluorescein diacetate indicates that this separation is associated with little detectable cell damage. This endocarp tissue can be challenged with suspensions of macroconidia to initiate the "nonhost" resistance response against the bean pathogen, $F u$ sarium solani f. sp. phaseoli. The germ tube growth of this fungus

Corresponding author: L. A. Hadwiger; E-mail address: chitosan@wsu.edu

* The $e$-Xtra logo stands for "electronic extra" and indicates that Figure 1 appears in color online.

doi:10.1094/PHYTO-98-4-0372

(C) 2008 The American Phytopathological Society is totally suppressed within $6 \mathrm{~h}$. Alternately, the growth of the true pathogen of pea, F. solani f. sp. pisi, is partially suppressed at $6 \mathrm{~h}$, but resumes growth within $12 \mathrm{~h}$, eventually initiating a fullfledged infection. The rapidity of the interaction between the fungus spores and the individual surface cells of pea endocarp occurs because there are many individual fungal cells on individual host cells signaling the molecular and biological changes. Further, the challenging spores have not penetrated the plant's cells and can be quantitatively removed up to $6 \mathrm{~h}$ postinoculation. With this synchronization and sensitivity it is possible to detect early signaling events that initiate the resistance response. Cruickshank and Perrin (18), who introduced this system, typically detected pisatin accumulations in pea endocarp tissue in response to nonhost fungal spores at $40 \mathrm{~h}$ postinoculation. However, alterations such as changes in the density of nuclei of the upper endocarp cells occur within $20 \mathrm{~min}$ (31), which relate to the eventual outcome of the interaction. That is, the density of the nuclei, detected by sedimentation rates, is considerably less from surface pea cells altered by the pathogen and somewhat less dense from cells altered by the nonpathogen than the density of nuclei recovered from the water-treated tissue.

\section{CONTRIBUTIONS OF THE PEA SEEDLING SYSTEM}

The cuticle barrier. Enzymes released from fungi are potential enhancers of both the pathogenicity and virulence of the pathogen. It appears that the absence of any single enzyme-encoding gene researched to date is not sufficient to totally negate the pathogenicity of $F$. solani f. sp. pisi. However, enhanced expression of certain fungal-derived genes appears to increase virulence. One such enzyme from $F$. solani f. sp. pisi is cutinase. This enzyme was first purified in 1975 (68). Antibodies developed against this enzyme or specific inhibitors of serine hydrolases, both of which inhibit cutinase activity, reduced the capacity of the fungus to penetrate the cuticle of the pea in stem section assays (61). The results of these investigations and others suggest that cutinase enzyme activity was important for penetrating the cuticle barrier. Subsequently, an $F$. solani f. sp. pisi cutinase-deficient mutant of isolate T-8 was found to have an 80 to $90 \%$ reduction in enzyme activity and a $45 \%$ reduction in pathogenicity compared with the wild type (20). 
Both the cloning of the cutinase gene that made possible mutation by gene replacement and the availability of the Nectria haematococca, mating population VI (sexual stage), F. solani f. sp. pisi (anamorph) that allowed the genetic crossing, enabled Stahl and Schafer (76) to investigate the role of cutinase directly by the construction of a cutinase-deficient mutant by gene replacement. A number of these transformants showed no difference in pathogenicity and virulence on pea compared with the wild type and a control transformant. This led to the suggestion that cutinase was not as important in pathogenicity as previously proposed. It was subsequently reported (56) that the apparent lack of dependence on cutinase was because the highly virulent strains of $F$. solani $\mathrm{f}$. sp. pisi have multiple cutinase genes, enabling the transformants to retain virulence. This conclusion was based on inoculations with the $F$. solani f. sp. pisi isolate, 77-2-3, which has one cutinase gene, and $\mathrm{T}-8$, which has multiple cutinase genes and is hypervirulent. Isolate $77-2-3$ had 10 to $20 \%$ of the cutinase activity of isolate T-8. Furthermore, lesion formation was less frequent and less severe for the cutinase-gene-disrupted mutant of 77-2-3.

Additional work on the regulation of cutinase expression revealed that there are two cutinase gene promoters. The promoter of a gene termed cut 2 is constitutively expressed in $F$. solani f. sp. pisi, but its expression is higher under starvation conditions. The promoter for gene cut 1 is highly induced by cutin monomers. This differential expression was related to the palindrome binding protein (PBP) binding to the respective promoters. PBP is thought to interfere with the binding of a transcription factor (TF), CTF1, involved in induction of cutinase (58).

Because other nonpathogenic (e.g., saprophytic) fungi also possess cutinase-producing capabilities (45), this enzyme is clearly not the sole component determining pathogenicity in $F$. solani $\mathrm{f}$. sp. pisi. However, the observation that cutinase expression in spores of $N$. haematococca can be induced by monomers of cutin (85) indicates that it is likely to be involved in penetration of the cuticle layer. This explanation for transgressing the cuticle in the pea-Fusarium interactions appears to be better documented than that for direct entrance via physical pressure from a penetration peg.

Pisatin degradation and $F$. solani f. sp. pisi virulence. Research on the pathogen's ability to degrade the phytoalexin, pisatin, has provided insight into the virulence of the $F$. solani $\mathrm{f}$. sp. pisi pathogen. The VanEtten Laboratory investigated the capacity of the $F$. solani $\mathrm{f}$. sp. pisi $\mathrm{P} 450$ enzyme, later termed pisatin demethylase (PDA), to degrade the phytoalexin, pisatin (23). Was this degradation potential the basis for $F$. solani $\mathrm{f}$. sp. pisi being a pathogen of pea (73)? PDA assays performed with an array of isolates of $F$. solani $\mathrm{f}$. sp. pisi suggested that the more virulent of these isolates could also more readily degrade pisatin (81). The ability to make crosses in $N$. haematococca mating population VI's (80) along with the cloning of the pisatin demethylase gene (84) made possible a genetic analysis of PDA in relation to virulence. The genetic analyses of a number of isolates of Nectria haematococca ( $F$. solani f. sp. pisi) indicated that multiple genes control pathogenicity on pea $(52,60,78)$. The gene considered particularly important was Pda coding for PDA. All naturally occurring isolates without the PDA gene $(P d a-)$ were essentially nonpathogenic on peas. $P d a$ - mutants of a virulent $F$. solani $\mathrm{f}$. sp. pisi isolate, created by transformation-mediated gene disruptions, were modestly reduced in virulence (83). As a bonus, these disruptions allowed the detection of other pathogenicity genes that were also located on dispensable chromosomes of this fungus $(43,51,79,83)$. The possibility was proposed that, analogous to bacterial plasmids, these dispensable DNA containing segments may control or influence the fungal host range.

The $P D A 1$ gene was also transferred to a pathogen of another host to determine if the transgenic pathogen would acquire a capability to infect pea (73). Reportedly, some virulence potential, based on lesion diameter, was donated to the recipient. Thus, it is currently evident that the lack of the production of pisatin demethylase does not totally negate the $N$. haematococca virulence potential and its presence may not be the sole virulence determinant, but it does contribute to virulence (50).

\section{MOLECULAR BIOLOGY OF THE PEA DISEASE RESISTANCE RESPONSE-PEA ENDOCARP SYSTEM}

PR genes (proteins) and disease resistance. In pea, the single dominant gene resistance against races of $F$. oxysporum pv. pisi and Pseudomonas syringae pv. pisi as well as the nonhost resistance to $F$. solani f. sp. phaseoli involves some of the same PR genes $(19,35,42)$. There are at least two lines of evidence that this disease resistance response (37) requires RNA and protein synthesis. First, by the use of specific inhibitors such as $\alpha$-amanitin, which inhibits DNA-dependent RNA polymerase, cordycepin, which blocks the transfer of mRNA out of the nucleus, and cycloheximide, which inhibits protein synthesis, it is possible to determine the vital time following inoculation when the inhibition of each of these processes can no longer block the resistance response $(36,37)$. Secondly, a striking loss of potential to generate the nonhost resistance via PR proteins was evident, monitored by mycelial growth and the mRNA-coded protein accumulation that occurs, following a $2-\mathrm{h}$ heat treatment at $40^{\circ} \mathrm{C}$. This loss of resistance is accompanied by the redirection, at the RNA level, of protein synthesis from normally increasing PR-specific message toward the increased synthesis of heat shock proteins (41). Following this heat shock, the potential to activate the synthesis of PR proteins is negated. After a 9-h recovery period, endocarp tissue recovers the potential to activate PR genes and simultaneously regains the potential to regenerate resistance. The PR gene products were identified using a process that is currently considered "proteomics." The pea mRNA extracted from each treatment was translated into protein in the presence of a labeled amino acid with an in vitro protein synthesizing system, and the induced proteins were detected as intense exposure spots with $\mathrm{X}$ ray film following a two dimensional gel separation. This correlative loss and regeneration of disease resistance with PR protein synthesis is a strong indication of the need for the induction of PR proteins.

Nonhost resistance and $\mathbf{R}$-gene resistance involve the same PR genes. In contrast to the initial communications of singledominant-gene determinants of the gene-for-gene interactions, a considerable number of genes are induced at the PR gene level in nonhost resistance. Over 200 potential PR genes associated with the nonhost resistance response were first selected (on the basis of enhanced expression) from a pea cDNA library (72). Some of the same PR genes are activated in both gene-for-gene and nonhost resistance reactions (19). Nine genes whose induction best followed the actual expression of resistance were selected for further study. Assays for (i) the activation of these PR genes, (ii) cytological detection of the growth of the fungus, and (iii) the observation of the hypersensitive response provided a simple and direct means for monitoring the resistance response (44).

\section{PEA PR GENES WITH KNOWN FUNCTIONS}

PAL. The PAL gene family codes for the phenylalanine ammonia-lyase enzyme (48) which catalyzes the first step in the phenylpropanol pathway toward biosyntheses of lignin, pisatin, etc.

CHS. CHS codes for chalcone synthase (46), an enzyme required for isoflavonoids such as pisatin.

DRR206. DRR206 codes for an enzyme $(22,27)$ in the lignin/ lignan pathway.

DRR49, DRR276. These pea genes code for a protein homologous with RNase $(65,72)$.

Chitinase gene codes for chitinase (11) an enzyme digesting chitin, a fungal cell wall component. 
$\beta$-glucanase codes for an enzyme digesting $\beta$-glucans, fungal wall components (10).

pI39, pI230. These pea genes code for high cysteine content proteins $(12,28)$ called defensins.

Antifungal products of pea PR genes: Defensins. Defensins are antifungal products of some PR genes. Some of the first defensin genes cloned, pI39 and pI230, came from pea $(7,12)$. These two genes, now named DRR39 and DRR230, are actively expressed in the pea endocarp during the resistance response against $F$. solani f. sp. phaseoli (28). The predicted amino acid sequence from DRR39 has 95\% identity with a peptide $P s d \mathrm{I}$ isolated from pea seeds. The gene product of $P s d \mathrm{I}$ was shown to possess high antifungal activity at concentrations ranging from 0.04 to $22 \mu \mathrm{g} / \mathrm{ml}(2,3)$. The defensins are usually lower molecular weight proteins (peptides) possessing high levels of the amino acid cysteine (3). The biological activity of the pea defensins corresponds to that of similar highly conserved antimicrobial peptides present in a broad range of biological organisms (75). Defensins can induce the membrane destabilization/permeabilization important for fungal growth (57). Some defensins also have been shown to inhibit protein synthesis, enzyme activity, and ion channels. Plant defensins form a characteristic structure known as the cysteine-stabilized $\alpha / \beta$ motif, a feature that is also shared by several toxins from insects, scorpions, honeybees, and spider venoms. The only residues that are absolutely conserved are the eight cysteines and a glycine residue (position 34). When pea defensin gene DRR230 is overexpressed in canola, extracts of these plants inhibited the in vitro germination of Leptosphaeria maculans, the causal agent of blackleg (82). Some intact transformant adult plants were significantly more resistant than controls to blackleg. This pea defensin gene was also utilized in the biological control of blue mold of apple (47).

Other PR gene products. Direct antifungal action has been proposed for products of other PR genes such as those coding for chitinase and $\beta$-glucanase. Although increases in these enzymes in the pea endocarp system are evident beginning at $10 \mathrm{~h}$ after inoculation with $F$. solani f. sp. phaseoli, they are also initially present $(62,63)$, albeit in lesser amounts, in healthy tissue. Because many fungi have substrates of both enzymes, chitin and $\beta$ glucan, within their cell walls, the proposed action of these enzymes in the interaction with the plant has been related to their combined potential to degrade the cell wall at the mycelial apex, exposing the fragile plasma membrane. Indeed, membranes do burst when exposed to high concentrations of $\beta$-glucanase and chitinase (64). Furthermore, there is a release of chitosan from $F$. solani f. sp. phaseoli when the walls are exposed to these enzymes (49). Chitinase attacks the $\mathrm{N}$-acetylglucosamine polymers (within chitin) and possibly because native chitin is partially deacetylated, there is a release of deacetylated fragments (chitosan is $80 \%$ deacetylated chitin). The biologically active oligomers of chitosan possess seven or more residues and are released in greater quantity from $F$. solani $\mathrm{f}$. sp. phaseoli than from $F$. solani f. sp. pisi. Chitosan is a potent inhibitor of $F$. solani spore germination and mycelial growth (49).

Analysis of pea PR gene contributions by transformation. Both the pea gene PR10 (formerly DRR49), which possesses homology with a plant RNase (65), and the pea chitinase gene were transformed into canola with little or no enhancement of resistance to blackleg (82). Transgenic 'Shepody' potatoes possessing the pea gene DRR49 displayed resistance to potato early dying disease (Verticillium dahliae) (8). However, the utility of this gene is negated by the close homology of its product to other plant allergens (6). Overexpression of the pea chitinase and $\beta$ glucanase genes in potato often reduced plant size without significantly benefiting disease resistance (9). Expression of pea gene DRR206, encoding an enzyme in the lignan pathway (22) in canola, conferred resistance to blackleg (82). In general, transfer of individual pea and other plant PR genes to different crop plant species has only yielded incremental increases in resistance, rather than full immunity (67). Total immunity may require multiple PR genes.

Preformed antifungal compounds in peas. Pea tissues possess abundant saponins that possibly contribute to the antifungal properties of this tissue, again without accounting for full immunity (16).

Regulation within the fungus. Although the morphological development, detected cytologically, of $F$. solani when exposed to pea endocarp tissue differs between the bean and pea pathogens, the growth of both is initially suppressed within $6 \mathrm{~h}$. A percentage of mycelia of the true pea pathogen ( $F$. solani $\mathrm{f}$. sp. pisi) can resume growth within $18 \mathrm{~h}$; however, the nuclei in the nongrowing hyphal tips of the bean pathogen ( $F$. solani f. sp. phaseoli) are visibly fragmented (53). While it is logical to look for antifungal components generated from the plant defense side, it is entirely possible for the fungus to control, in part, its own destiny. For example, as the disease progresses, there is a thickening of fungal walls very reminiscent of the fungus's ability to acquire the dormancy and morphology of chlamydospores (77). These changes are similar to those that occur when spores are held in arid soil or when exposed to other stresses independent of the host response. Also, there is an accumulation of the DNase in $F$. solani f. sp. phaseoli beginning with germination (53). The production of DNase by the fungus could have evolved from a need to recover nutrients such as the nucleotides and bases of DNA from older mycelia. The premature accumulation of DNase in younger mycelia could account for the observed nuclear fragmentation, an attribute of programmed cell death, that likely suppresses the pathogen's growth. The plant's role in this scenario may reside in its ability to initially slow pathogen growth, allowing this premature DNase accumulation to occur. The generally better condition of the true pathogen's nuclei remains unexplained.

Summary statement of some plant mechanisms for slowing fungal growth. Some components with potential for slowing fungal growth include saponins, the cuticle barrier, cell wall components (e.g., callose, lignin, etc.), pisatin accumulation, enzymic digestion by chitinase and $\beta$-glucanase, chitosan oligomers, and defensins.

Techniques for monitoring pathogen effects in the presence of pharmaceuticals with specified modes of action. The condition of components of pea endocarp cells, primarily nuclear alterations, can readily be viewed with appropriate stains within the critical 6-h period required for resistance development (13, 53). Ultimately, the DNA sequences from selected PR genes have been used to assess gene activity by real-time PCR or northern analyses $(28,44)$. Also, DNA damage assessments were assayed by TUNEL ( $\underline{T} d T-m e d i a t e d ~ d \underline{U T P}$ nick-end-labeling) assays and polyacrylamide gel electrophoresis separations of isolated DNA (53). In addition to analyzing changes by pathogens, the simplicity of these direct monitoring techniques has enabled the pharmaceutical evaluation of the effect of most known cell regulating compounds on the development of resistance over a broad range of concentrations (44). In the absence of a cuticle, most compounds are readily taken up by the endocarp cells. These sensitive assays also provided insight into how various chemical structures can initiate or affect the development of the defense responses. Earlier research examined many of the commercially available compounds as elicitors (38-40), whereas later evaluations utilized 40 known inhibitors that affect vital plant cell processes or contribute to the blockage or accumulation of the signaling initiators reported in Arabidopsis and other nonlegume systems (44). Remarkably, the resistance of pea legume tissue was not detectably altered by elicitors such as jasmonic acid, salicylic acid, nitric oxide, or superoxides. Additionally, these screenings found that compounds serving as precursors to these latter elicitors do not enhance induction significantly, and at high concentrations can negatively affect resistance. 
The pea endocarp tissue can be, and has been, used to test many commercially available regulatory compounds for their ability to activate pisatin synthesis. Cruickshank and Perrin (18) determined early that low concentrations of heavy metals could efficiently elicit pisatin accumulations. Subsequently, it was observed that compounds that intercalate, alter, or helically distort DNA could also induce pisatin $(34-39,66)$. Most importantly this simple system can provide an accurate assessment of any yet to be discovered regulatory compound or component with a potential to alter the disease resistance responses.

Mode of action of biotic elicitors. The natural defense response of pea is elicited by fungal-derived chitosan oligomers and/or a DNase enzyme, and both are known to be released from F. solani f. sp. phaseoli. These two components are categorized as "biotic inducers." "Fsph DNase" $(29,53)$ and chitosan $(32,49)$ significantly stimulate both the pea defense response and total immunity to $F$. solani $\mathrm{f}$. sp. pisi. Chitosan is a polycationic polymer of $\beta$-1,4-linked glucosamine residues (32). An explanation is warranted to explain how chitosan and Fsph DNase with such diverse characteristics may both manipulate similar nonhost resistance responses. Chitosan as a polycationic molecule requires a substantially higher concentration $(>20 \mu \mathrm{g} / \mathrm{ml})$ to elicit this response (32) than the Fsph DNase, which elicits at extremely low levels (53). There is evidence that both elicitors enter the pea cell and the pea nucleus $(29,36)$. Fsph DNase is a single-strand nicking enzyme and can cause DNA degradation. This may explain the previously mentioned changes in nuclear density. Chitosan, in a manner similar to other basic polymers, associates with the negatively charged phosphates of nuclear DNA (36), possibly causing the exclusion or alteration of normal cellular proteins that are also basically charged (37) and consequently chromatin coformational changes.

Potential role of HMG A. HMG A (formerly HMG-I/Y) has previously been shown in animal systems to have profound effects on chromatin structure and the activation of genes by associating with AT-rich regions in vital areas of the gene promoters (4, 69,70), some of which are present in PR gene promoters (55). HMG A has been described as an architectural TF. In the pea endocarp system, it has been shown to complex with AT-rich regions within the DRR206 promoter sequence (54), which are vital for induction of DRR206. Further, both the transcribed HMG A message and the detectable HMG A protein are diminished within $6 \mathrm{~h}$ after inoculation, but to a greater extent with $F$. solani f. sp. pisi than with $F$. solani $\mathrm{f}$. sp. phaseoli inoculations. The pea HMG A protein is endowed with conserved amino acid motifs (PRGRP) that form "AT-hook" structures (55). In other eukaryotic systems, these AT-hooks are known to insert within the minor groove of double-stranded AT-rich DNA. This association can be altered by phosphorylation (88). That is, the more this TF is phosphorylated, the less secure the association. Because of the strong conservation of the vital HMG A amino acid sequences between plants and animals, much of what is learned about gene regulation in animal systems can be directly utilized in this pea system.

Phosphatase inhibition and the manipulation of resistance. In pea endocarp tissue it was observed that the following parameters could be enhanced or altered using specific inhibitors of phosphatases: pathogen growth, pisatin accumulation, hypersensitive discoloration, PR gene activation, and DNA damage (44). Calyculin $\mathrm{A}$ is a phosphatase 1 and $2 \mathrm{~A}$ inhibitor, and at 0.15 and $10 \mu \mathrm{g} / \mathrm{ml}$, it induces pisatin accumulations of 46 and $286 \%$, respectively, compared with that induced by treatment with spores of the nonpathogen of pea, F. solani f. sp. phaseoli. Calyculin A at the higher concentration $(10 \mu \mathrm{g} / \mathrm{ml})$ can break the nonhost resistance to this fungus, even in the presence of accumulations of $>200 \mu \mathrm{g}$ of pisatin per gram of tissue. Thus, the potential benefit of these high levels of pisatin is apparently negated by an interference with another component needed in resistance. On the other hand, lower concentrations ( 0.03 to $0.07 \mu \mathrm{g} / \mathrm{ml}$ ) of calyculin A can temporarily enhance the pea tissue's resistance to the true pathogen of pea, F. solani f. sp. pisi. Resistance can similarly be manipulated with okadaic acid, which also inhibits phosphatases 1 and 2A. Many legume proteins are selectively phosphorylated in response to pathogen challenge (26) or when tissues are subjected to these phosphatase inhibitors. Other legumes also experience enhanced production of flavonoid compounds and plant defenses $(30,59)$ following treatment with phosphatase inhibitors.

Phosphorylation and the regulation of PR gene transcription. In pea, the low concentrations of both calyculin $\mathrm{A}(0.003 \mu \mathrm{g} / \mathrm{ml})$ and okadaic acid $(0.0028 \mu \mathrm{g} / \mathrm{ml})$ enhanced the expression of pea PAL and CHS genes within $5 \mathrm{~h}$ (44). Preliminary results from $\mathrm{P}^{32} \mathrm{O}_{4}$-labeled pea endocarp tissue indicated that the rate of HMG A phosphorylation was severely reduced within $4 \mathrm{~h}$ after inoculation with the pathogen, $F$. solani $\mathrm{f}$. sp. pisi, and partially reduced by the nonpathogen, F. solani f. sp. phaseoli (S. Hartney and L. A. Hadwiger, unpublished data). If the plant scenario is analogous with that observed in animal cells, the reduced levels of HMG A phosphorylation should enable the HMG A protein's AT-hooks to better fit the AT-rich regions of PR gene promoters thereby increasing expression $(25,88)$. The status-quo phosphorylation level of HMG A protein in nonchallenged pea tissue would be less able to bind the PR (and other promoters), possibly by preventing the chromatin remodeling required for the expression of certain PR genes. Alternatively, enhanced binding at another chromosomal location could likely give reverse effects.

The more nonspecific challenge of chromatin structure by the biotic elicitor, Fsph DNase, is likely to activate PR genes by a different mechanism. Because DNA is wrapped around nucleosomes, the single-stranded DNase cleaving action may directly affect nucleosome conformation (Fig. 1).

Gene transcription and nucleosome condition. Recent work with nucleosomes $(1,21)$ indicates that following nucleosome disassembly, certain genes therein can be actively transcribed without the requirement of TFs. However, this TF specificity returns after the nucleosome is re-assembled. The complexity of chromatin modeling and transcription is likely to remain mysterious in the foreseeable future; however, the pea endocarp system provides a degree of synchronization useful in detecting changes in individual nuclear proteins. The pea system can be up-scaled sufficiently to enable the purification of the nuclear proteins for analyses by mass spectrophotometry of any modifications, analyses that are difficult using genetic approaches. The disadvantage of this system remains the difficulty of cell culture and regeneration of pea tissue, which discourages permanent gene transfers or replacements (87). The use of transient transformation techniques can partially compensate for this deficiency.

Outlook for alternative approaches to manipulate resistance. Understanding how to manage the concerted induction of multiple PR genes may have more promise than overexpressing individual PR genes in manipulating immunity or high levels of resistance. Each of the two elicitors released by $F$. solani f. sp. phaseoli, Fsph DNase and chitosan, have the capability of inducing complete resistance to the true pathogen $F$. solani $\mathrm{f}$. sp. pisi $(49,53)$. The possibility of obtaining resistance, via the engineering within the plant of the multi-step biosynthetic pathway of chitosan, is problematic (9). However, a single fungal gene codes for Fsph DNase (53). The cloned Fsph DNase gene was then used in transformation experiments to assess if overexpression would lead to disease resistance. Here, a region of the promoter from pea gene DRR206, which responds to many pathogen challenges (14), was used. This construct was able to provide a high level of immunity in tobacco to moderate inoculum levels of Pseudomonas syringae pv. tabaci (14). However, the same construct transferred to potato provided little protection against Phytophthora infestans, probably because the potato tissue had a greater sensitivity to DNase. If the resistance that results in complete 
immunity is due to an assembly of multiple PR gene contributions, it will be important to determine how this array of enhanced gene expression occurs.

Researchers are now reexamining the potential of chromatin changes to alter gene activation $(69,71)$. HMG A proteins, previously mentioned, become a part of chromatin, which mainly consists of the nucleosomes that are repeating units along the DNA. The nucleosome has a central $\mathrm{H} 3$ histone/ $\mathrm{H} 4$ histone tetramer flanked on both sides by H2A histone/H2B histone dimers (86) (Fig. 1). When transcription levels of the gene-containing DNA wrapped around the nucleosome are very high, histones can be transiently displaced. However, most of the transcribed genes retain a nucleosomal organization that the polymerase II (Pol II) of the polymerase complex must confront (74). During nucleo- some traversal by Pol II, a single $\mathrm{H} 2 \mathrm{~A} / \mathrm{H} 2 \mathrm{~B}$ dimer is released. A recent report indicates that there is a considerable DNA sequence and orientation-dependent variation in both the overall height and location of the nucleosome transcription barrier (5). Thus, nucleosomes are not uniform in the strength of these barriers to elongation by Pol II. Also, other mechanisms are needed to inflict the transient loss of the $\mathrm{H} 2 \mathrm{~A} / \mathrm{H} 2 \mathrm{~B}$ dimer (75). The enhancement of transcription that has been associated with total nucleosome disassembly (1) may also be related to PR gene induction. Additionally, if future studies in plants also detect weaker nucleosome barriers in the vicinity of the PR genes, this may help explain why the PR genes are induced preferentially over the many other host genes following inoculation with the fungus. The preliminary observations on changes in HMG A in pea and the accumulating

\section{Bean Pathogen: Nonhost response, total resistance}

\section{True Pea Pathogen: Partial resistance, then susceptibility}

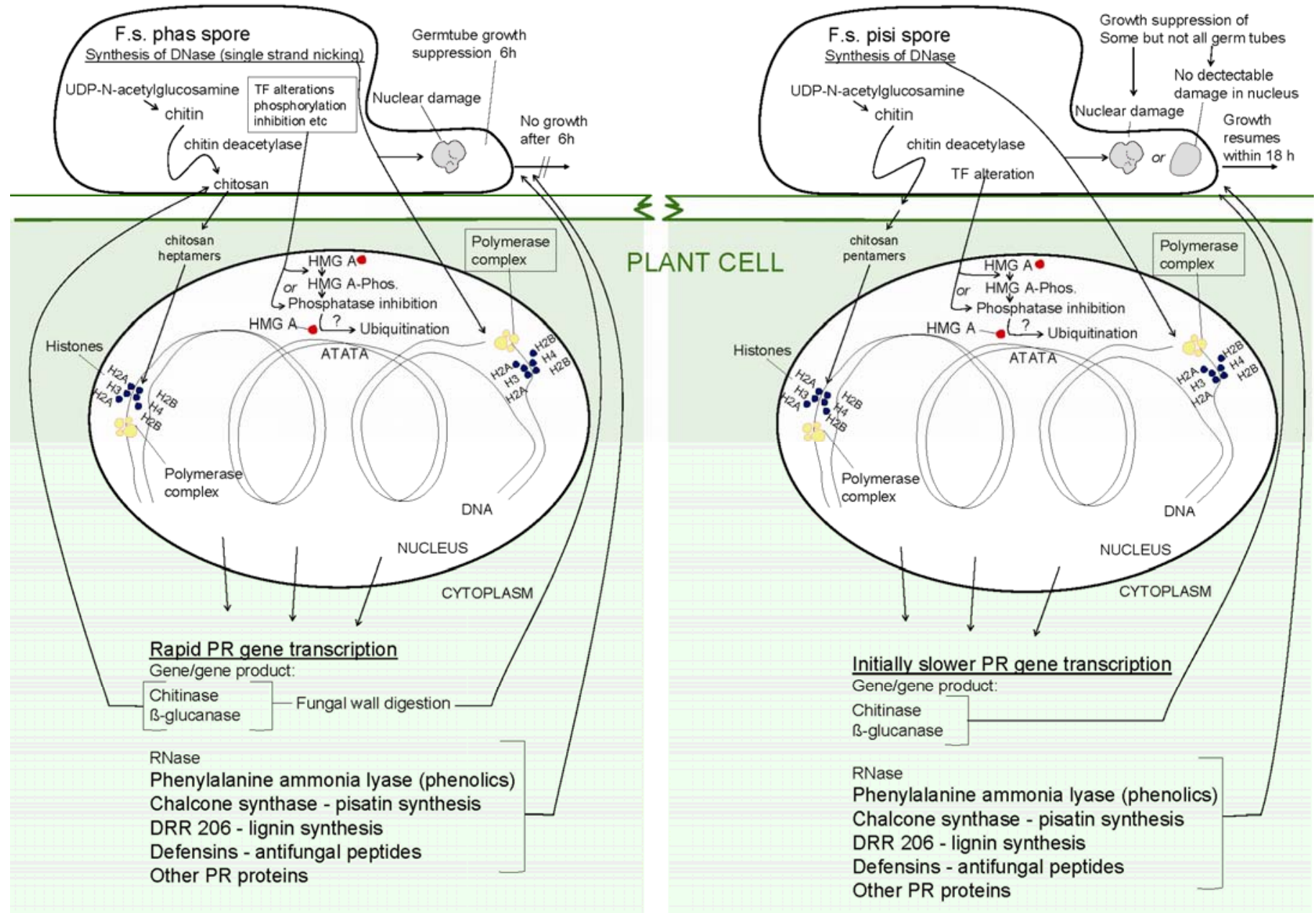

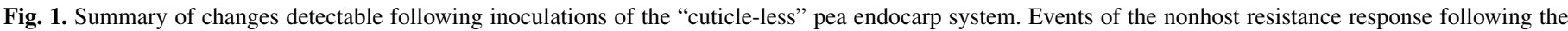

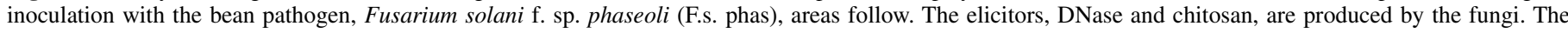

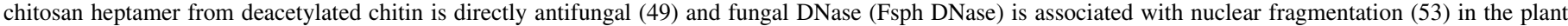

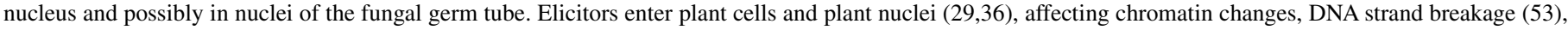

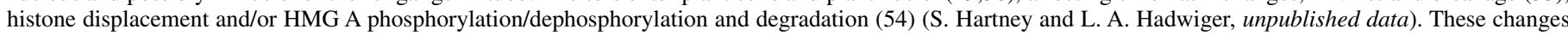

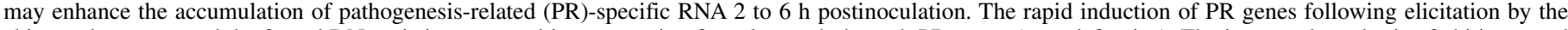

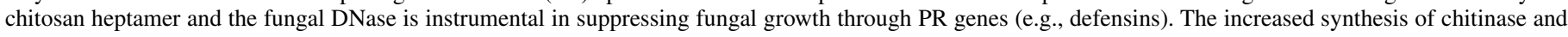

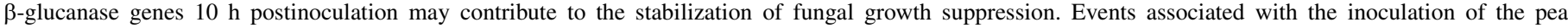

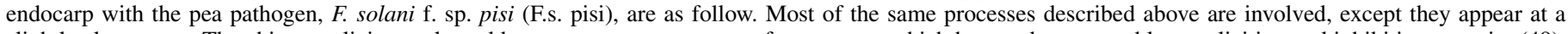

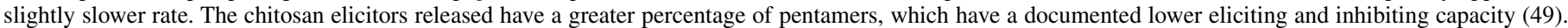

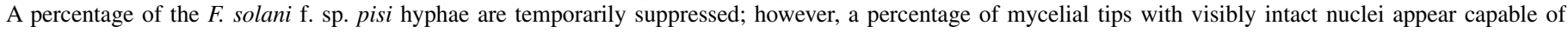

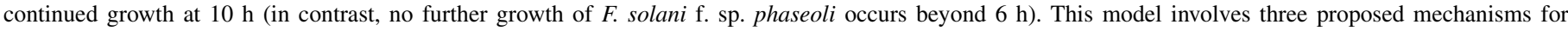

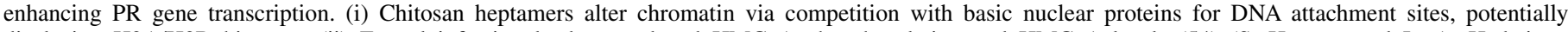

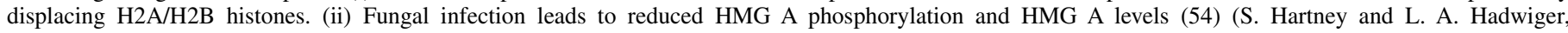

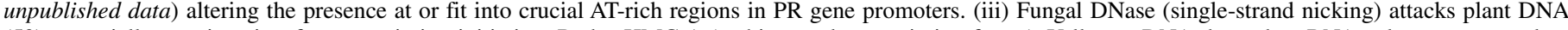

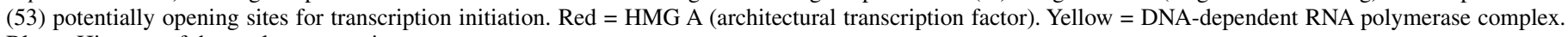
Blue $=$ Histones of the nucleosome units. 
data on histone modifications observed in other eukaryotic systems warrant further investigations that may help determine if and how the two are related in plant defense responses.

In summary, the PR gene elicitors chitosan and Fsph DNase may affect chromatin modeling in the following manners (Fig. 1): (i) chitosan as a polycationic molecule may compete with histones and other nuclear proteins for sites on the DNA; (ii) Fsph DNase as a single-strand DNA nicking enzyme may dramatically loosen the helical condensation of nuclear DNA. Other fungalinitiated signals may affect PR gene transcription by altering state of phosphorylation, methylation, or ubiquitination of HMG A, histones and/or other proteins. As indicated, the phosphorylation of HMG A has been shown to suppress its association with ATrich sites on promoter DNA (25). The challenges of pea tissue with $F$. solani $\mathrm{f}$. sp. phaseoli or $F$. solani $\mathrm{f}$. sp. pisi both promote a lower rate of phosphorylation of some nuclear proteins and the eventual disappearance of HMG A, a development that could also change promoter functions (54).

The microarray and proteomic techniques currently utilized to determine the differential expression of genes and their protein products often identify, as did previous library screenings (72), multiple hundreds of genes associated with disease resistance and other stress responses. Because it appears that overexpressed single PR genes can rarely lead to engineering complete immunity to pathogen infection, it may be more productive to strive for manipulative control over multiple genes at the chromatin level rather than in engineering single genetic traits.

Hopefully this review will encourage the continued examination of the biochemistry and molecular cell biology of nuclear proteins, and to the use and development of intact tissue models such as the pea endocarp, to further our understanding of the gene activation associated with disease resistance. Tools that will favor the pea endocarp system include the cloned PR genes, cloned fungal genes, defined biotic elicitors, cytological and biochemical monitoring capabilities of intact tissue, and synchronized resistance development. The completed sequence of the $N$. haematococca (F. solani f. sp. pisi) will also be a very useful tool for this system.

As an update on the genome sequencing, the following communication is from H. VanEtten at the University of Arizona: $N$. haematococca mating population VI has been sequenced by the DOE Joint Genome Institute (JGI) and is available online by JGI.

Nectria sp. has one of the largest genome $(\approx 60 \mathrm{Mb})$ of any sequenced ascomycete. The isolate sequenced is pathogenic on pea and having this sequence should help to identify those genes specifically involved in pathogenesis on pea as well as identifying the genes that allow this ubiquitously distributed fungus to colonize a wide variety of habitats.

A diagramed summation of some points presented in this review is presented in Figure 1.

\section{ACKNOWLEDGMENTS}

I thank the Washington Sea Grant Program for research support and X. Chen, J. Isaac, R. L. Gilbertson, and H. D. VanEtten for manuscript review. PPNS no. 0456, Department of Plant Pathology, Agricultural Research Center, Washington State University.

\section{LITERATURE CITED}

1. Adkins, M. W., and Tyler, J. K. 2006. Transcriptional activators are dispensable for transcription in the absence of Spt6-mediated chromatin reassembly of promoter regions. Mol. Cell 21:452-453.

2. Almeida, M. S., Cabral, K. M. S., Kurtenbach, E., Almeida, F. C. S., and Valente, A. P. 2002. Solution structure of Pisum sativum defensin 1 by high resolution NMR: Plant defensins, identical backbones with different mechanisms of action. J. Mol. Biol. 315:749-757.

3. Almeida, M. S., Cabral, K. M. S., Zingali, R. B., and Kurtenbach, E. 2000. Characterization of two novel defense peptides from pea (Pisum sativum) seeds. Arch. Biochem. Biophys. 378:278-286.
4. Banks, G. C., Li, Y., and Reeves, R. 2000. High-mobility group A1a protein regulates RasERK signaling in MCF-7 human breast cancer cells. Biochemistry 39:8333-8346.

5. Belotserkovskaya, R., Oh, S., Bondarenko, V. A., Orphanides, G., Studitsky, V. M., and Reinberg, D. 2003. FACT facilitates transcriptiondependent nucleosome alteration. Science 301:1090-1093.

6. Breiteneder, H., Pettenburger, K., Bito, A., Valenta, R., Kraft, D., Rumpold, H., Scheiner, O., and Breitenbach, M. 1989. The gene coding for the major birch pollen allergen Betv 1 is highly homologous to a pea disease resistance response gene. EMBO J. 8:1935-1938.

7. Broekaert, W. F., Terras, F. R. G., Cammue, B. P. A., and Osborn, R. W. 1995. Plant defensins: Novel antimicrobial peptides as components of the host defense system. Plant Physiol. 108:1353-1358.

8. Chang, M.-M., Chiang, C. C., Martin, M. W., and Hadwiger, L. A. 1993. Expression of a pea disease resistance response gene in the potato cultivar shepody. Am. Potato J. 70:635-647.

9. Chang, M.-M., Culley, D., Choi, J. J., and Hadwiger, L. A. 2002. Agrobacterium-mediated co-transformation of a pea $\beta$-1,3-glucanase and chitinase genes in potato (Solanum tuberosum L. cv. Russet Burbank) using a single selectable marker. Plant Sci. 163:83-89.

10. Chang, M. M., Hadwiger, L. A., and Horovitz, D. 1992. Molecular characterization of a pea $\beta$-1,3-glucanase induced by Fusarium solani and chitosan challenge. Plant Mol. Biol. 20:609-618.

11. Chang, M. M., Horovitz, D., Culley, D., and Hadwiger, L. A. 1995. Molecular cloning and characterization of a pea chitinase gene expressed in response to wounding, fungal infection and the elicitor chitosan. Plant Mol. Biol. 28:105-111.

12. Chiang, C. C., and Hadwiger, L. A. 1991. The Fusarium solani-induced expression of a pea gene family encoding high cysteine content proteins. Mol. Plant-Microbe Interact. 4:324-331.

13. Choi, J. J., Klosterman, S. J., and Hadwiger, L. A. 2001. A comparison of the effects of DNA-damaging agents and biological elicitors on the induction of plant defense genes, nuclear distortion and cell death. Plant Physiol. 125:752-762.

14. Choi, J. J., Klosterman, S. J., and Hadwiger, L. A. 2004. A promoter from pea gene DRR206 is suitable to regulate an elicitor-coding gene and develop disease resistance. Phytopathology 94:651-660.

15. Christenson, J. A., and Hadwiger, L. A. 1973. Induction of pisatin formation in the pea foot region by pathogenic and nonpathogenic clones of Fusarium solani. Phytopathology 63:784-790.

16. Christian, D. A., and Hadwiger, L. A. 1989. Pea saponins in the peaFusarium solani interaction. Exp. Mycol. 13:419-427.

17. Cruickshank, I. A. M., and Perrin, D. R. 1961. Studies on phytoalexins III. The isolation assay, and general properties of a phytoalexins from Pisum sativum L. Austral. J. Biol. Sci. 336-348.

18. Cruickshank, I. A. M., and Perrin, D. R. 1963. Studies on phytoalexins VI. Pisatin: The effect of some factors on its formation in Pisum sativum and the significance of pisatin in disease resistance. Austral. J. Biol. Sci. 16:111-128.

19. Daniels, C. H., Fristensky, B., Wagoner, W., and Hadwiger, L. A. 1987. Pea genes associated with non-host disease resistance to Fusarium are also active in race-specific disease resistance to Pseudomonas. Plant Mol. Biol. 8:309-316.

20. Dantzig, A. H., Zuckerman, S. H., and Andonov-Roland, M. M. 1986. Isolation of a Fusarium solani mutant reduced in cutinase activity and virulence. J. Bacteriol. 168:911-916.

21. Davie, J. K., and Dent, S. Y. R. 2006. No Spt6, no nucleosomes, no activator required. Mol. Cell 21:552-553.

22. Davin, L. B., Wang, H. B., Crowell, A. L., Bedgar, D. L., Martin, D. M., Sarkanen, S., and Lewis, N. G. 1997. Stereoselective bimolecular phenoxyradical coupling by an auxiliary (Dirigent) protein without an active center. Science 275:362-366.

23. Delserone, L. M., McCluskey, K. D., Mathews, E., and VanEtten, H. D. 1999. Pisatin demethylation by fungal pathogens and nonpathogens of pea: Association with pisatin tolerance and virulence. Physiol. Mol. Plant Pathol. 55:317-326.

24. DiCenzo, G. L., and VanEtten, H. D. 2006. Studies on the late steps of (+) pisatin biosynthesis: Evidence for $(-)$ enantiomeric intermediates. Phytochemistry 67:675-683.

25. Edberg, D. D., Adkins, J. N., Springer, D. L., and Reeves, R. 2005. Dynamic and differential in vivo modifications of the isoform HMGA1a and HMG1b chromatin proteins. J. Biol. Chem. 280:8961-8973.

26. Felix, G., Regenass, M., Pietro, S., and Boller, T. 1994. The protein phosphatase inhibitor calyculin A mimics elicitor action in plant cells and induces rapid hyperphosphorylation of specific protein as revealed by pulse labeling with $\left[{ }^{33} \mathrm{P}\right]$ phosphate. Proc. Natl. Acad. Sci. USA 91:952956.

27. Fristensky, B., Horovitz, D., and Hadwiger, L. A. 1988. cDNA sequences from pea disease resistance response genes. Plant Mol. Biol. 11:713-715.

28. Fristensky, B., Riggleman, C. R., Wagoner, W., and Hadwiger, L. A. 1985. 
Gene expression in susceptible and disease resistant interactions of peas induced with Fusarium solani pathogens and chitosan. Physiol. Plant Pathol. 27:15-28.

29. Gerhold, D. L., Pettinger, A. J., and Hadwiger, L. A. 1993. Characterization of a plant stimulated nuclease from Fusarium solani. Physiol. Mol. Plant Pathol. 43:33-46.

30. Gianfagna, T. J., and Lawton, M. A. 1995. Specific activation of soybean defense genes by the phosphoprotein phosphatase inhibitor okadiac acid. Plant Sci. 109:165-170.

31. Hadwiger, L. A., and Adams, M. J. 1978. Nuclear changes associated with the host-parasite interaction between Fusarium solani and peas. Physiol. Plant Pathol. 12:63-72.

32. Hadwiger, L. A., and Beckman, J. M. 1980. Chitosan as a component of pea Fusarium solani interactions. Plant Physiol. 66:205-211.

33. Hadwiger, L. A., Beckman, J. M., and Adams, M. J. 1981. Localization of fungal components in the pea-Fusarium interaction detected immunochemically with anti chitosan and anti-fungal cell wall antisera. Plant Physiol. 67:170-175.

34. Hadwiger, L. A., Chang, M.-M., and Parsons, M. A. 1995. Fusarium solani DNase is a signal for increasing expression of non-host disease resistance response genes, hypersensitivity and pisatin production. Mol. Plant-Microbe Interact. 8:871-879.

35. Hadwiger, L. A., Chiang, C. C., and Horovitz, D. 1992. Expression of disease resistance response genes in near-isogenic pea cultivars following challenge by Fusarium oxysporum race 1. Physiol. Mol. Plant Pathol. 40:259-269.

36. Hadwiger, L. A., Chiang, C., Victory, S., and Horovitz, D. 1989. The molecular biology of chitosan in plant/pathogen interaction and its application in agriculture. Pages 119-138 in: Chitin and Chitosan. G. Skjak-Braek, T. Anthonsen, and P. Sandford, eds. Elsevier Applied Science, London.

37. Hadwiger, L. A., Jafri, A., Von Broembsen, S., and Eddy, R. 1973. Mode of pisatin induction: Increased template activity and dye-binding capacity of chromatin isolated from polypeptide-treated pea pods. Plant Physiol. 53:52-63.

38. Hadwiger, L. A., Loschke, D. C., and Teasdale, J. R. 1977. An evaluation of pea histones as disease resistance factors. Phytopathology 67:755-758.

39. Hadwiger, L. A., and Schwochau, M. E. 1970. Induction of phenylalanine ammonia lyase and pisatin in pea pods by poly-lysine spermidine or histone fractions. Biochem. Biophys. Res. Comm. 38:683-691.

40. Hadwiger, L. A., and Schwochau, M. E. 1971. Specificity of deoxyribonucleic acid intercalating compounds in the control of phenylalanine ammonia lyase and pisatin levels. Plant Physiol. 47:346351.

41. Hadwiger, L. A., and Wagoner, W. 1983. Effect of heat shock on the mRNA-directed disease resistance response of peas. Plant Physiol. 72:553-556.

42. Hadwiger, L. A., and Webster, D. M. 1984. Phytoalexin production in five cultivars of peas differentially resistant to three races of Pseudomonas syringae pv. pisi. Phytopathology 74:1312-1314.

43. Han, Y., Liu, X., Ulla, B., Kistler, H. C., and VanEtten, H. 2001. Genes determining pathogenicity to pea are clustered on a supernumerary chromosome in the fungal plant pathogen, Nectria haematococca. Plant J. 25:305-314.

44. Hartney, S., Carson, J., and Hadwiger, L. A. 2007. The use of chemical genomics to detect functional systems affecting the non-host disease resistance of pea to Fusarium solani f. sp. phaseoli. Plant Sci. 172:45-56.

45. Heinen, W., and de Vries, H. 1966. Stages during the breakdown of plant cutin by soil microorganisms. Arch. Microbiol. 54:331-338.

46. Ichinose, Y., Kawamata, S., Yamada, Y., An, C., Kauiwara, T., Shiraishi, T., and Oku, H. 1992. Molecular cloning of chalcone synthase cDNA from Pisum sativum. Plant Mol. Biol. 18:1009-1012.

47. Janisiewicz, W. J., Pereira, I. B., Almeida, M. S., Roberts, D. P., Wisniewski, M. E., and Kurtenbach, E. 2006. Biocontrol activity of recombinant Pichia pastoris constitutively expressing pea defensin against blue mold of apple. (Abstr.) Phytopathology 96(suppl.):S53.

48. Kawamata, S., Yamada, T., Tanaka, Y., Sriprasertsak, P., Kato, H., Ichinose, Y., Kado, H., Shiraishi, T., and Oku, H. 1992. Molecular cloning of phenylalanine ammonia-lyase. Plant Mol. Biol. 20:167-170.

49. Kendra, D. F., Christian, D., and Hadwiger, L. A. 1989. Chitosan oligomers from Fusarium solani/pea interactions, chitinase and $\beta$ glucanase digestion of sporelings and from fungal wall chitin actively inhibit fungal growth and enhance disease resistance. Physiol. Mol. Plant Pathol. 45:215-230.

50. Khan, R., and Straney, D. C. 1999. Regulatory signals influencing expression of the PDA 1 gene of Nectria haematococca MP VI in culture and during pathogenesis of pea. Mol. Plant-Microbe Interact. 12:733-742.

51. Kistler, H. C., Meinhardt, L. W., and Benny, U. 1996. Mutants of Nectria haematococca created by a site-directed chromosome breakage are greatly reduced in virulence toward pea. Mol. Plant-Microbe Interact.
9:804-809.

52. Kistler, H. C., and VanEtten, H. D. 1984. Regulation of pisatin demethylation in Nectria haematococca. and its influence on pisatin tolerance and virulence. J. Gen. Microbiol. 130:2605-13.

53. Klosterman, S. J., Chen, J., Choi, J. J., Chen, E. E., and Hadwiger, L. A. 2001. Characterization of a $20 \mathrm{kDa}$ DNase elicitor from Fusarium solani f. sp. phaseoli and its expression at the onset of induced resistance in Pisum sativum. Mol. Plant Pathol. 2:147-158.

54. Klosterman, S. J., Choi, J. J., and Hadwiger, L. A. 2003. Analysis of pea HMG-I/Y expression suggests a role in defense gene regulation. Mol. Plant Pathol. 4:249-258.

55. Klosterman, S. J., and Hadwiger, L. A. 2002. Plant HMG proteins bearing the AT hook motif. Plant Sci. 163:855-866.

56. Kolattukudy, P. E., Soliday, C. L., Woloshuk, C. P., and Crawford, M. 1985. Molecular biology of early events in the fungal penetration into plants. Pages 421-438 in: Molecular Genetics of Filamentous Fungi. W. F. Timberlake, ed. Alan R. Liss, Inc., New York.

57. Lay, F. T., and Anderson, M. A. 2005. Defensins - Components of the innate immune system in plants. Curr. Protein Peptide Sci. 2005:85-101.

58. Li, D., Sirakova, T., Rogers, L., Ettinger, W. F., and Kolattukudy, P. E. 2002. Regulation of constitutively expressed and induced cutinase genes by different zinc finger transcription factors in Fusarium solani f. sp. pisi (Nectria haematococca). J. Biol. Chem. 277:7905-7912.

59. Mackintosh, C., Lyon, G. D., and Mackintosh, R. W. 1994. Protein phosphatase inhibitors activate anti-fungal defense responses of soybean cotyledons and cell cultures. Plant J. 5:137-147.

60. Mackintosh, S. F., Matthews, D. E., and VanEtten, H. D. 1989. Two additional genes for pisatin demethylation and their relationship to the pathogenicity of Nectria haematococca on pea. Mol. Plant-Microbe Interact. 2:354-362.

61. Maiti, I. B., and Kolattukudy, P. E. 1979. Prevention of fungal infection of plants by specific inhibition of cutinase. Science 205:507-508.

62. Mauch, F., Hadwiger, L. A., and Boller, T. 1984. Ethylene: Symptom not signal for the induction of chitinase and $\beta$-1,3-glucanase in pea pods by pathogens and elicitors. Plant Physiol. 76:607-611.

63. Mauch, F., Hadwiger, L. A., and Boller, T. 1988. Antifungal hydrolases in pea tissue. I. Purification and characterization of two chitinases and two $\beta$-1,3-glucanases differentially regulated during development and in response to fungal infection. Plant Physiol. 87:325-333.

64. Mauch, F., and Staehelin, L. A. 1989. Functional implications of the subcellular localization of ethylene-induced chitinase and $\beta$-1,3-glucanase in bean leaves. Plant Cell 1:447-457.

65. Moiseyev, G. P., Beintema, J. J., Fedoreyeve, L. I., and Yakovlev, G. I. 1994. High sequence similarity between a ribonuclease from Ginseng calluses and fungus-elicited proteins from parsley indicates that intracellular pathogenesis-related proteins are ribonucleases. Planta 193:470-472.

66. Parsons, M. A., and Hadwiger, L. A. 1998. Photoactivated psoralens elicit defense genes and phytoalexins production in the pea plant. Photochem. Photobiol. 67:438-445.

67. Punja, Z. K. 2001. Genetic engineering of plants to enhance resistance to fungal pathogens-A review. Can. J. Plant Pathol. 23:216-235.

68. Purdy, R. E., and Kolattududy, P. E. 1975. Hydrolysis of plant cuticle by plant pathogens. Purification, amino acid composition and molecular weight of two isozymes of cutinase and a non-specific esterase from Fusarium solani f. pisi. Biochemistry 14:2824-2831.

69. Reeves, R. 2002. Molecular biology of HMG A proteins: Hubs of nuclear function. Gene 277:63-81.

70. Reeves, R., and Beckerbauer, L. 2001. HMG I/Y proteins: Flexible regulators of transcription and chromatin structure. Biochim. Biophys. Acta 1519:13-19.

71. Reeves, R., Edberg, D. D., and Li, Y. 2001. Architectural transcription factor HMGI(Y) promotes tumor progression and mesenchymal transition of human epithelial cells. Mol. Cell Biol. 21:575-594.

72. Riggleman, R. D., Fristensky, B., and Hadwiger, L. A. 1985. The disease resistance response in pea is associated with increased levels of specific mRNAs. Plant Mol. Biol. 4:81-86.

73. Schaffer, W., Straney, D., Cuiffetti, L., VanEtten, H. D., and Yoder, O. C. 1989. One enzyme makes a fungal pathogen, but not a saprophyte virulent on a new host. Science 246:247-249.

74. Schwabish, M. A., and Struhl, K. 2004. Evidence for eviction and rapid deposition of histones upon transcriptional elongation by RNA polymerase II. Mol. Cell. Biol. 24:10111-10117.

75. Selitrennikoff, C. P. 2001. Antifungal Proteins. Appl. Environ. Microbiol. 63:834-839. doi:10.1128/AEM.67.7.2883-2894.201.

76. Stahl, D. J., and Schafer, W. 1992. Cutinase is not required for fungal pathogenicity on pea. Plant Cell 4:621-629.

77. Teasdale, J., Daniels, D., Davis, W. C., Eddy, R., and Hadwiger, L. A. 1974. Physiological and cytological similarities between disease resistance and cellular incompatibility responses. Plant Physiol. 54:690-695. 
78. Tegtmeier, K. J., and VanEtten, H. D. 1982. The role of pisatin tolerance and degradation in the virulence of Nectria haematococca on peas: A genetic analysis. Phytopathology 72:608-612.

79. VanEtten, H., Funnell-Baerg, D., Wasmann, C., and McCluskey, K. 2004. Location of pathogenicity genes on dispensable Chromosomes in Nectria haematococca MPVI. Antonie van Leeuwenhoek 65:263-267.

80. VanEtten, H. D., and Kistler, H. C. 1988. Nectria haematococca mating populations I and VI: Genetics of pathogenic fungi. G. S. Sidhu, ed. Adv. Plant Pathol. 6:189-206.

81. VanEtten, H. D., and Matthews, P. S. 1984. Naturally occurring variation in the inducibility of pisatin demethylating activity in Nectria haematococca mating population VI. Physiol. Plant Pathol. 25:149-160.

82. Wang, Y., Nowak, G., Culley, D., Hadwiger, L. A., and Fristensky, B. 1999. Constitutive expression of pea defense gene DRR206 confers resistance to black leg (Leptosphaeria maculans) disease in transgenic canola (Brassica napus). Mol. Plant-Microbe Interact. 12:410-418.

83. Wasmann, C. C., and VanEtten, H. D. 1996. Transformation-mediated chromosome loss and disruption of a gene for pisatin demethylase decrease the virulence of Nectria haematococca on pea. Mol. Plant-
Microbe Interact. 9:793-803.

84. Weltring, K.-M., Turgeon, B. G., Yoder, O. C., and VanEtten, H. D. 1988. Cloning a phytoalexin-detoxification gene from the plant pathogenic fungus Nectria haematococca by detecting its expression in Aspergillus nidulans. Gene 68:335-344.

85. Woloshuk, C. P., and Kollatukudy, P. E. 1986. Mechanism by which contact with plant cuticle triggers cutinase gene expression in the spores of Fusarium solani. Proc. Natl. Acad. Sci. USA 83:1704-1708.

86. Wood, C. M., Nicholson, J. M., Lambaert, S. J., Chantalat, L., Reynolds, C. D., and Baldwin, J. P. 2005. High-resolution structure of the native histone octamer. Acta. Cryst. F61:541-545.

87. Wu, Q., and VanEtten, H. D. 2004. Introduction of plant and fungal genes into pea (Pisum sativum S.) hairy roots reduces their ability to produce pisatin and affects their response to a fungal pathogen. Mol. PlantMicrobe Interact. 17:798-804.

88. Xiao, D.-M., Pak, J. H., Wang, X., Sato, T., Huang, F. L., Chen, H.-C., and Huang, K.-P. 2000. Phosphorylation of HMG-1 by protein kinase C attenuates its binding affinity to the promoter regions of protein kinase $\mathrm{C}$ gamma and Neurogranin/RC3. J. Neurochem. 74:392-399. 